\title{
Confocal laser scanning microscopy of peritoneal catheter surfaces
}

\author{
S. P. GORMAN, W. M. MAWHINNEY, C. G. ADAIR and M. ISSOUCKIS*
}

School of Pharmacy, The Queen's University of Belfast, Medical Biology Centre, Belfast BT9 7BL and "Leica UK Ltd, Know/hill, Milton Keynes MK5 8LB

\begin{abstract}
Summary. Surface topography of used (in situ $>12$ months) and unused CAPD catheters was studied by scanning electronmicroscopy (SEM) and confocal laser scanning microscopy (CLSM). Microbial biofilm was observed on all used catheters. Disruption and removal of the attached biofilm revealed extensive pitting of the catheter surface and scoring within the catheter pores. Similar, though less extensive, surface defects were present in unused catheters. Examination by CLSM, with software specific to the determination of surface topography, showed used catheters to have a surface microrugosity greater than that of unused catheters $(\mathrm{p}<0.0005)$. Adherence studies with radiolabelled Staphylococcus epidermidis demonstrated increased adherence to used than to unused catheters $(\mathrm{p}<0.0005)$ after $48 \mathrm{~h}$. However, when catheters were pre-treated with spent dialysate there was a substantial reduction in bacterial adherence to either catheter and no significant difference in adherence to used and unused catheters. Surface microrugosity of CAPD catheters increases during use but is unlikely to be an important factor in bacterial adherence in vivo.
\end{abstract}

\section{Introduction}

Peritonitis is the major complication associated with continuous ambulatory peritoneal dialysis (CAPD) in the treatment of end-stage renal failure. ${ }^{1}$ Examination of catheters removed from CAPD patients often reveals the presence of microbial biofilm, a complex structure which forms on the surface of biomaterials by the growth of adherent micro-organisms exuding an exopolysaccharide matrix or glycocalyx. ${ }^{2}$ This thick mucoid mass offers protection from host immunedefence mechanisms, antibiotics and biocides and is of vital importance in the persistence of many severe or recurrent infections. ${ }^{3}$ Surface adhesion of bacteria is an initial event in the pathogenesis of bacterial infection associated with biomaterials-without which colonisation fails, biofilm formation does not occur and the infective process is not sustained. ${ }^{4}$ The process of microbial adherence is complex, involving electrostatic attraction (Van der Waal's forces) and the hydrophobic or hydrophilic properties and surface energy of the biomaterial. ${ }^{5}$

Surface topography, including the degree of surface roughness or microrugosity, plays an important role in initial bacterial adherence. Implants with porous surfaces are much more susceptible to infection after implantation as micro-organisms tend to sequester themselves in cavities and avoid host defences. ${ }^{6}$ Muller et al..$^{7}$ found that prosthetic silicone implants which were relatively smooth tended to develop cracks and

Received 22 June 1992: accepted 16 Oct. 1992. fissures with extended wear, allowing anchor sites for bacteria. Similarly, grooves or roughened surfaces on CAPD catheters have been shown by Fessia et al ${ }^{8}$ to provide niches and crevices which encourage bacterial adhesion and biofilm formation. They concluded that commercially available catheters varied in their susceptibility to biofilm formation due to their degree of surface microrugosity.

Confocal laser scanning microscopy (CLSM) has features common to light and electronmicroscopy and affords penetrative views of specimens. By the use of point scanning rather than full field illumination and a pinhole arrangement, optical sectioning is possible. Instead of scanning in the $x, y$ plane, it is possible to scan in the $x, z$ plane, allowing subsequent reconstruction of three-dimensional (3D) images. ${ }^{2}$ CLSM offers optimum clarity and resolution of fine surface detail and such data can be electronically manipulated to create $3 \mathrm{D}$ and topographical images. The aim of this study was to investigate if time-induced changes occurred in the surface microrugosity of indwelling CAPD catheters and to examine the implications of such surface changes for bacterial adherence.

\section{Materials and methods}

\section{$C A P D$ catheter collection and preparation}

Tenckhoff peritoneal catheters were collected aseptically over an 18-month study period. These became available following surgical removal because of recurrent peritonitis, catheter blockage, patient un- 
suitability for CAPD or from patients with no clinical infection after renal transplantation. Six catheters that had been in situ for $>12$ months were selected for examination; three unused, sterile catheters were used as controls.

Sections $(1 \mathrm{~cm})$ were cut from the intraperitoneal region and split longitudinally. One portion was retained for culture (see below). The other portion was cleaned by mild, intermittent ultrasonication (three $\times 20 \mathrm{~min}$ ) in sterile water. Cleaning was verified by microscopy. Control catheters were treated similarly by ultrasonication before investigation.

\section{Bacterial culture and identification}

Biofilm attached to the catheter surface was dislodged into sterile spent dialysate by a combination of gentle scraping, vortex mixing ( $30 \mathrm{~s})$ and ultrasonication ( $30 \mathrm{~s}$ in a $150 \mathrm{~W}$ ultrasonic bath operating at a nominal frequency of $50 \mathrm{~Hz}$ ). Disrupted biofilm was examined for growth on Columbia Blood Agar (Oxoid) and isolated micro-organisms were identified as described by Ludlam et al. (1989). ${ }^{9}$

\section{Scanning electronmicroscopy (SEM)}

Cleaned catheter portions were dehydrated through a $30,50,75,90$ and $100 \%$ ethanol series, allowing $30 \mathrm{~min}$ in the lower concentrations progressing to $60 \mathrm{~min}$ in the higher concentrations. They were then dried at the critical point of $\mathrm{CO}_{2}$ and coated with goldpalladium. Prepared samples were scanned with a Jeol 35 CF Microscope.

\section{Confocal laser scanning microscopy}

Cleaned catheter portions were attached to glass microscope slides with epoxy resin and, if required, stained with acridine orange $(0.05 \% \mathrm{w} / \mathrm{v}$ in $0.1 \mathrm{M}$ sodium citrate buffer, $\mathrm{pH} \mathrm{6.6)} \mathrm{for} 3 \mathrm{~min}$. Samples were examined in reflection at a wavelength of $488 \mathrm{~nm}$ with a Leitz confocal laser scanning microscope with long working distance lenses ( $40 \times 0.70$ PL Fluotar). Micrographs were produced on a freeze frame Polaroid video unit.

The image processing software of the microscope included simulated fluorescence processing (SFP or shadow-imaging), topographical imaging with measurement line (TML) and topographical image with 3D plot (T3D). The latter allowed measurement of the ratio of the $3 \mathrm{D}$ surface area to the area of the projection of the surface on to a plane to give a measure of the surface roughness. In all cases measurements were taken in three areas deemed typical for the catheter and all catheters were assessed for statistical analysis.

\section{Radio-isotopic assessment of bacterial adherence to catheter surface}

The radio-isotope assay employed by Gorman et al. $^{10}$ was modified to compare the adherence of a CAPD catheter biofilm isolate to control (unused) and long-dwell catheters. One colony of Staphylococcus epidermidis, isolated from a catheter biofilm was inoculated into $100 \mathrm{ml}$-Tryptone Soya Broth (Oxoid) containing $800 \mu \mathrm{l}$ of $\left(2-{ }^{3} \mathrm{H}\right)$-adenine $(37 \mathrm{MBq} / \mathrm{ml})$ and incubated for $18 \mathrm{~h}$ at $37^{\circ} \mathrm{C}$ in a shaking water bath. The suspension was centrifuged $\left(5000 \mathrm{~g}, 15 \mathrm{~min} 4^{\circ} \mathrm{C}\right)$, washed three times in cold phosphate-buffered saline (PBS, 0.01 M, pH 7.3) and the supernate was suspended in PBS to give $c .10^{8} \mathrm{cfu} / \mathrm{ml}$. Viable counts were determined by serial dilution and plating on Tryptic Soya Agar (Oxoid) by the drop plate method. Plates were incubated at $37^{\circ} \mathrm{C}$ for $24-48 \mathrm{~h}$ and the number of colonies was counted. Scintillation cocktail $(5 \mathrm{ml}$; OptiPhase "Hi Safe" 3, LKB, Leics.) was vortex mixed with $1 \mathrm{ml}$ of bacterial suspension for $1 \mathrm{~min}$ and the radioactivity was counted in a liquid scintillation system (1215 Rackbeta II, LKB). Four vials were counted and labelling efficiency was calculated by dividing the viable count by the average disintegrations/min (dpm).

Control (unused) and long-dwell catheter (18 months in situ) sections $(0.5 \mathrm{~cm}$ long) were pre-soaked in PBS or artificial spent dialysate ${ }^{11}$ at $37^{\circ} \mathrm{C}$ for $1 \mathrm{~h}$, rinsed three times in cold PBS and incubated under static conditions in radiolabelled bacterial suspension $(20 \mathrm{ml})$ at $37^{\circ} \mathrm{C}$ in $25-\mathrm{ml}$ glass screw-capped sterile bottles. At specified times over $120 \mathrm{~h}$, four catheter sections were removed with sterile forceps and washed gently five times in cold PBS to remove non-adherent bacteria. The final washing was checked to ensure that it was free from radioactivity. Each section was then placed in a glass scintillation vial, vortex mixed for $1 \mathrm{~min}$ with $5 \mathrm{ml}$ scintillation fluid and counted as before. The number of $\mathrm{dpm}$ was obtained for each catheter section and the $\mathrm{cfu} / \mathrm{cm}^{2}$ of catheter surface was calculated.

\section{Statistical analysis}

Three catheters from the used and unused groups were assessed in the adherence assay. All readings were made in quadruplicate and statistical comparison between groups was by unpaired $t$ test (two-way) ${ }^{12}$ In all cases a $\mathrm{p}$ value $<0.05$ was considered to be statistically significant.

\section{Results}

SEM of control catheters showed deep scoring of the outer surface, particularly within the catheter pores (fig. 1a). Numerous other surface defects were apparent on the catheter outer surface and included depressions or pits ranging in diameter from $200 \mu \mathrm{m}$ to $1 \mu \mathrm{m}$ (fig. 1b). Biofilm was observed by SEM on all six CAPD catheters removed from patients (not shown); the presence of viable $S$. epidermidis within the biofilm 

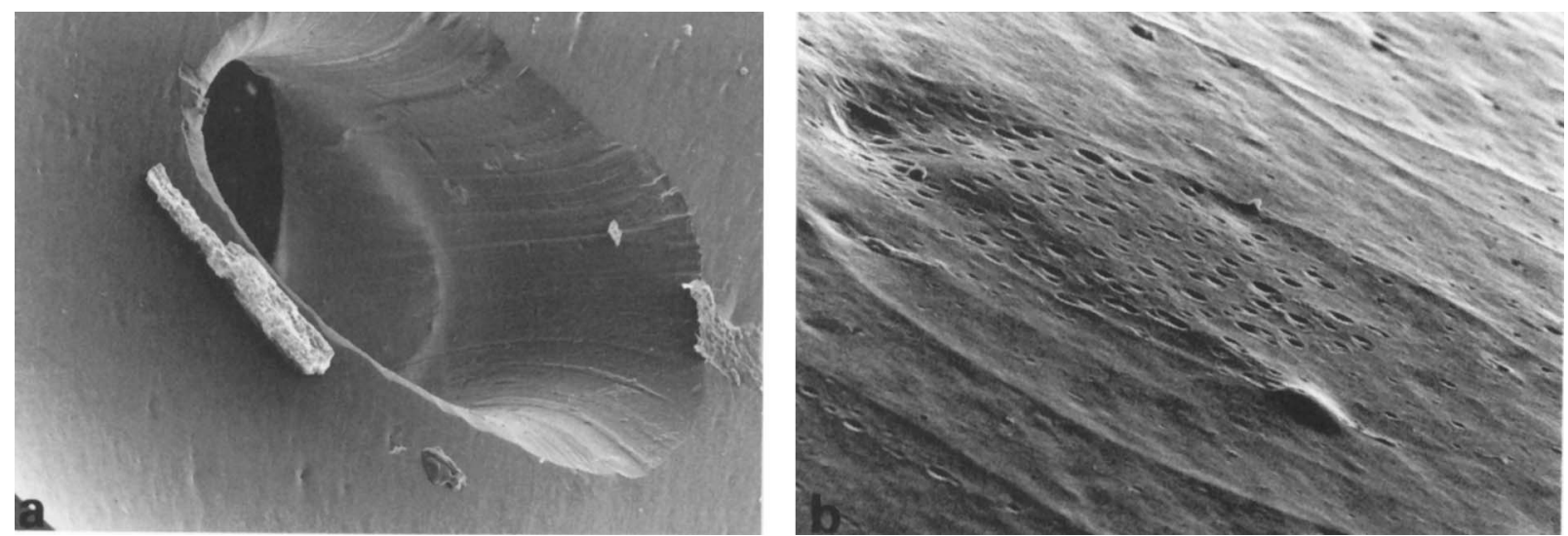

Fig. 1. SEM of unused CAPD catheters showing: a, scoring and pitting of the outer surface and pore (bar $=100 \mu \mathrm{m})$; $\mathbf{b}$, at higher magnification, numerous pits and depressions (bar $10 \mu \mathrm{m}$ ).

a

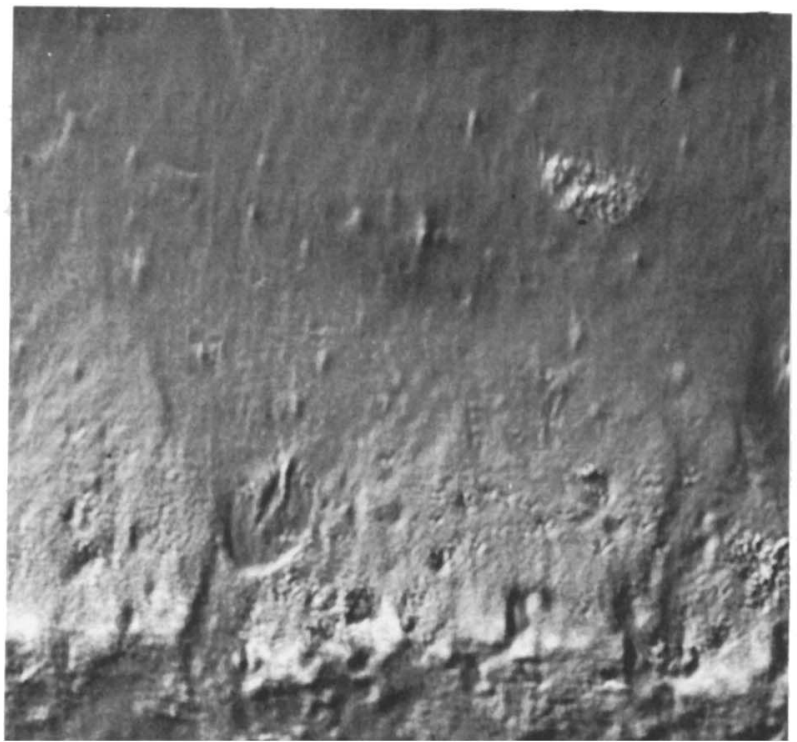

b

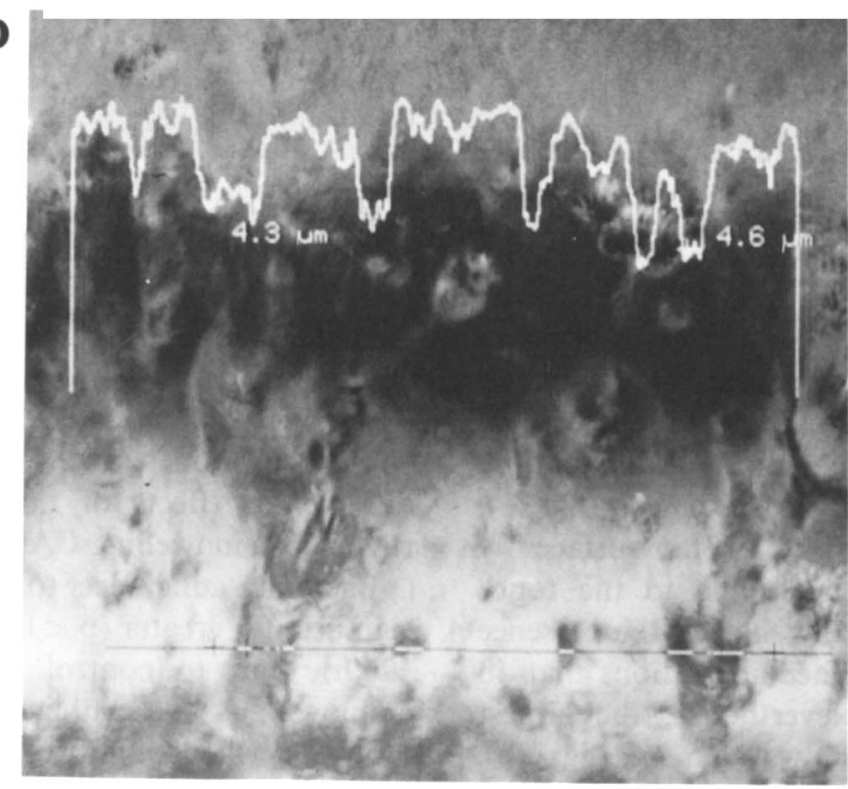

reflection

confocal

40.0/0.70 T

$\mathrm{xy}: 101 \times 101 \mu \mathrm{m}$

AM3

SFP

$10 \mu \mathrm{m}$

reflection

confocal

40.0/0.70 T

xy: $101 \times 101 \mu m$

AM3

TOPO

$10 \mu \mathrm{m}$

Fig. 2. CLSM of a used CAPD catheter (in situ 18 months): $\mathbf{a}$, in simulated fluorescence processing mode; $\mathbf{b}$, by topographical imaging of the same area and application of a measurement line to quantify surface microrugosity (bar $=10 \mu \mathrm{m}$ ).

was confirmed by culture. Biofilm was often associated with both catheter pores and surface.

Application of CLSM simulated fluorescence pro- cessing showed large grooves and ridges in those catheters in situ for $>12$ months (fig. 2a). The topographical image of the same area with measure- 


\section{a}

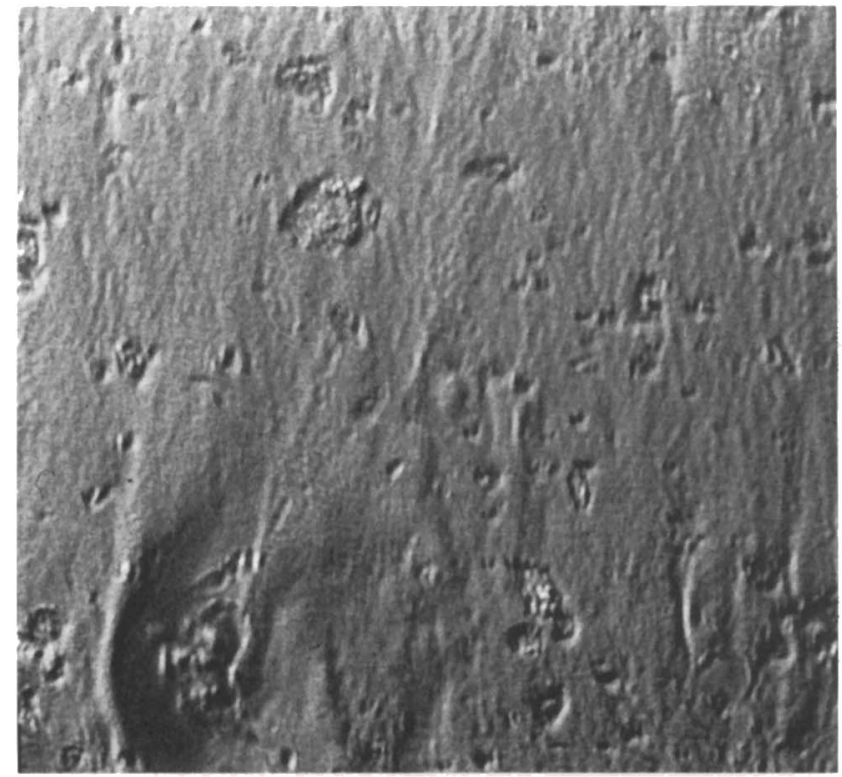

b

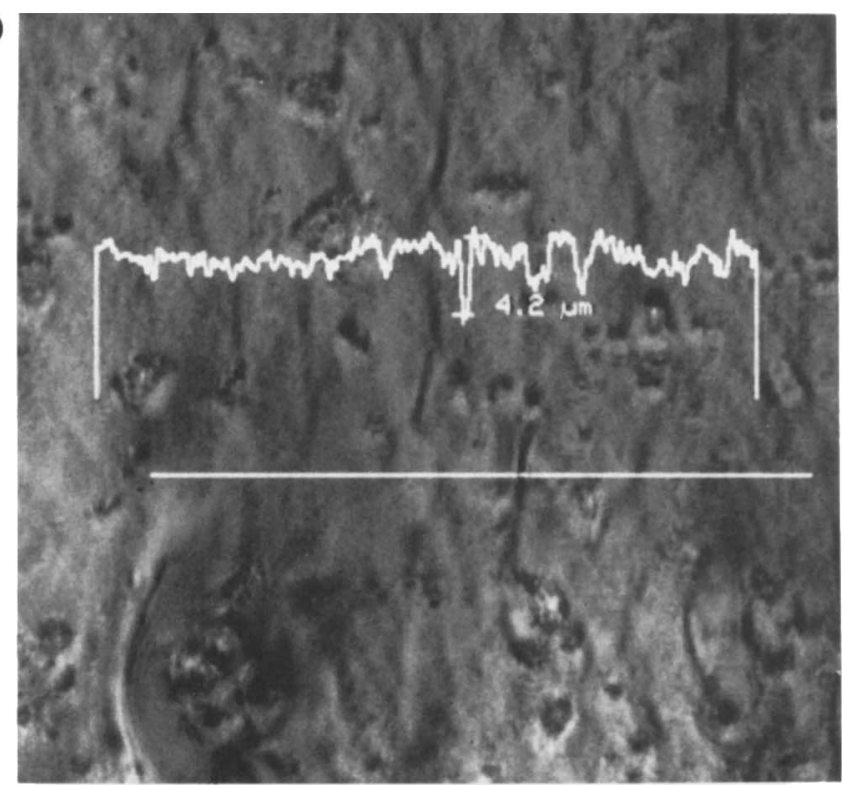

reflection

confocal

40.0/0.70 T

$x y: 101 \times 101 \mu \mathrm{m}$

AM2

SFP

$10 \mu \mathrm{m}$

reflection

confocal

40.0/0.70 T

$x y: 101 \times 101 \mu \mathrm{m}$

AM2

TOPO

$10 \mu \mathrm{m}$

Fig. 3. CLSM of an unused CAPD catheter: $\mathbf{a}$, in simulated fluorescence processing mode; $\mathbf{b}$, by topographical imaging of the same area and application of a measurement line to quantify the surface microrugosity (bar $=10 \mu \mathrm{m}$ ).

ment line (fig. 2b) allowed estimation of the "peaktrough" heights of the surface. Peak-trough measurements on long-dwell catheters ranged up to $7 \cdot 2 \mu \mathrm{m}$. Examination of the control catheters by CLSM also showed numerous surface defects (fig. 3a). Further study of the control catheter surface by application of the measurement line to the topographical surface view typically showed the presence of smaller, more regular surface aberrations than in the long-dwell catheters. Nevertheless, the largest peak-trough height observed was $4.5 \mu \mathrm{m}$ (fig. $3 \mathrm{~b}$ ). Application of the measurement line is subjective and the resulting peak-trough heights may be misleading. However, further data were obtained from 3D contour maps of the long-dwell and control catheter surfaces (fig. 4a and b). Employing 3D imaging allowed comparison of the area of the catheter surface with the area of the original surface projected onto a plane. The contour maps provided values (mean $\pm 95 \% \mathrm{CI}$ ) of $4.65 \pm 0.12$ for long-dwell catheters and $3.70 \pm 0.13$ for control catheters showing the significant $(p<0.0005)$ detrimental effects of time on the surface microrugosity of indwelling CAPD catheters.

Bacterial adherence to long-dwell catheters was significantly greater $(\mathrm{p}<0.005$ at $48 \mathrm{~h}, \mathrm{p}<0.0005$ at $120 \mathrm{~h}$ ) than to control catheters when PBS was employed as the catheter bathing fluid (fig. 5a). However, when long-dwell and control catheters were pre-treated with dialysate, adherence of bacteria was reduced $>10$-fold (fig. $5 b$ ) and bacterial adherence to long-dwell and control catheters was not significantly different $(\mathrm{p}>0 \cdot 1)$. 

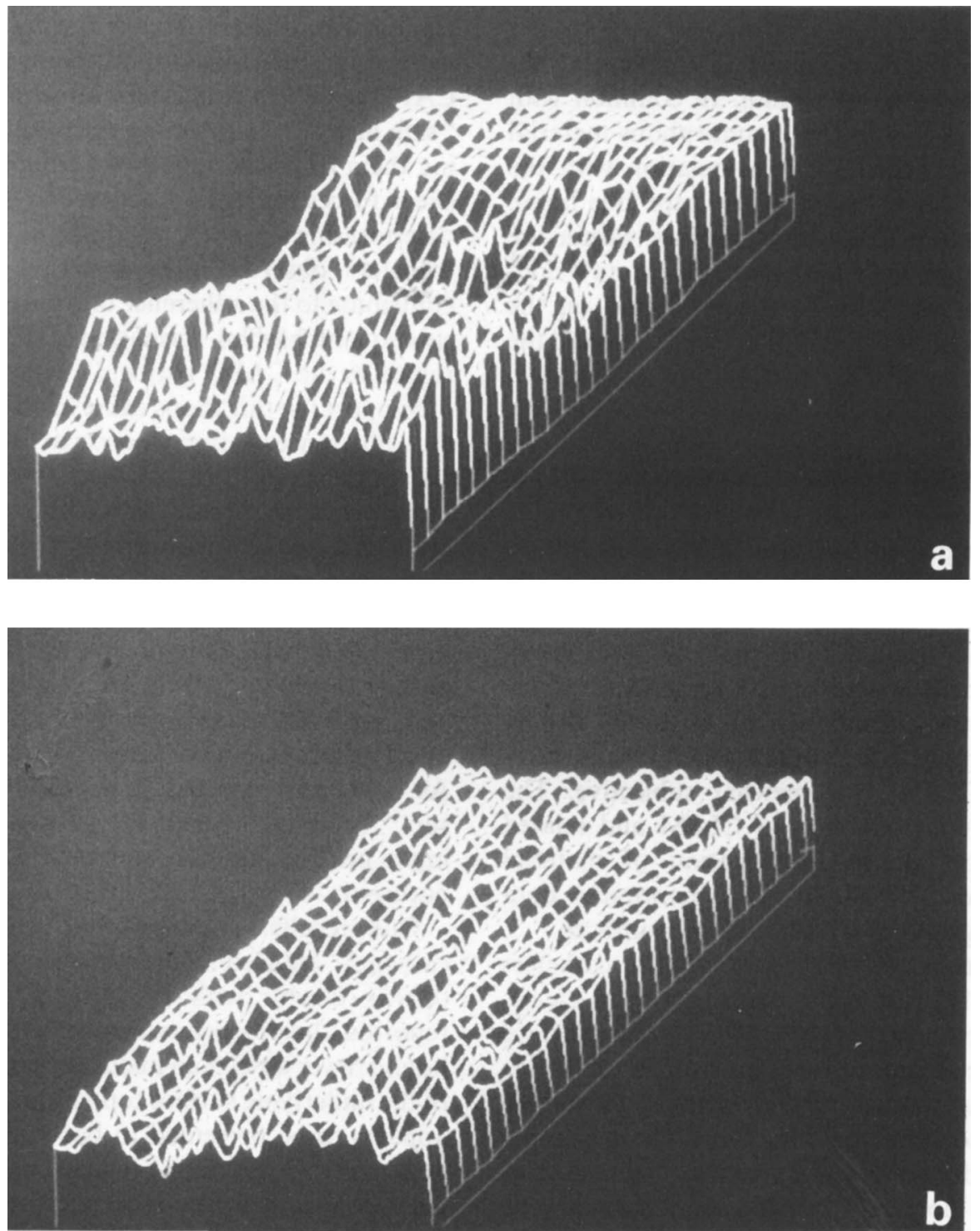

Fig. 4. Contour map representation of the CAPD catheter surface areas described in figs. 2 and 3 obtained by CLSM: a, used catheter; $\mathbf{b}$, unused catheter.

a

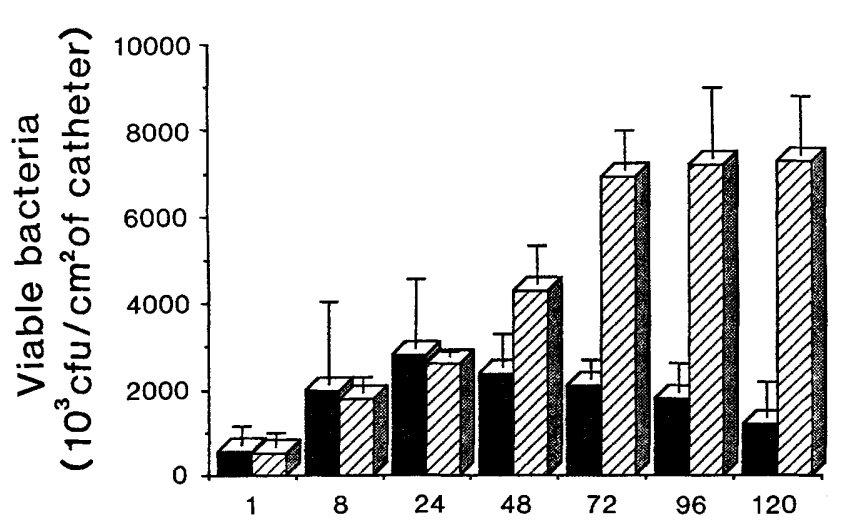

b

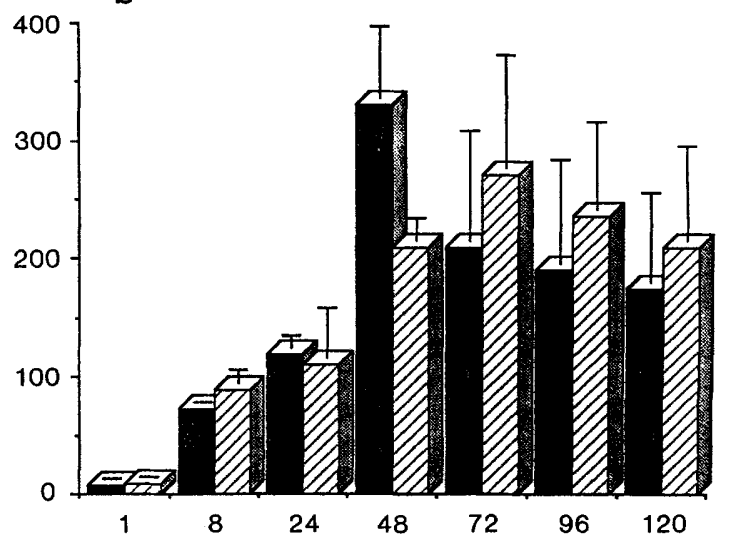

Time $(h)$

Fig. 5. Adherence (mean with $95 \%$ confidence intervals) of $S$. epidermidis to long-dwell (18 months in situ) ( $\square$ ) and unused (control) ( $\square)$ catheters pretreated with: a, phosphate buffered saline; $\mathbf{b}$, artificial spent dialysate. 


\section{Discussion}

All CAPD catheters examined in this study had associated viable bacterial biofilm. In common with Diaz-Blanco et al. ${ }^{13}$ who found amorphous material attached in greatest density in association with the surface irregularities of endotracheal tube side holes, we observed biofilm to be most profuse within the CAPD catheter pores. In long-dwell catheters a considerable biofilm was also frequently found on the catheter surface. SEM examination clearly showed the scoring and pitting of these surfaces but gave only a qualitative assessment of surface microrugosity. Quantitative data on surface roughness can be obtained by SEM through application of the associated waveform monitor line and this technique has been used to provide evidence of the contributory nature of surface microrugosity to bacterial adhesion on polymer microfilaments. ${ }^{14}$ However, the disadvantage of this technique is that all parameters employed, such as magnification and angle of incidence of electron bombardment, must be strictly controlled and, as with the application of the measurement line in CLSM, is somewhat subjective. The relatively recent introduction of CLSM and related software appropriate to investigation of material surfaces enabled us to obtain good quantitative data on the microrugosity of CAPD catheter surfaces.

Our investigations on unused catheters demonstrated that the manufacturing process causes pitting and deep scoring of the CAPD catheter surface and pores. Examination of long-dwell catheters showed that substantial further changes in surface topography also appeared with time. These changes may be the product of the in-vivo environment such as the long-term flow of the dialysis fluids or the degradative action of exudates from the attached microbial biofilm. The potential of microbial products to damage metal surfaces has been established ${ }^{15}$ when adherent bacterial cells were removed from the metal, intense pitting of the surface was revealed emphasising the importance of bacterial adherence in the corrosion process. Surface roughness measurements and electronmicroscopy of abraded metal surfaces have also indicated that there is a greater chance of bacterial retention within surface irregularities allowing protection from shear forces during cleaning. ${ }^{10}$ The surface irregularities in both control and indwelling CAPD catheters could offer attachment points and a "safe haven" for infecting micro-organisms, protecting them from the action of antibiotics and from the shear forces exerted by active dialysis. The apparent deteriorating surface topography of indwelling CAPD catheters observed over a period of months may contribute to the adherence of bacteria to the catheter, subsequent biofilm formation and, eventually, peritonitis in the CAPD patient.

Support for this thesis came from our initial finding that adherence of staphylococci to long-dwell catheters was significantly greater than to control catheters. However, artificial surfaces in contact with body fluids are rapidly coated with proteins which mask surface properties and alter non-specific and specific adherence. ${ }^{17}$ When long-dwell and control catheters were pre-treated with dialysate, to simulate in-vivo conditions, bacterial adherence was reduced $>10$-fold and, furthermore, differences in attachment to longdwell and control catheters were no longer apparent. As has been reported previously for Pseudomonas spp. ${ }^{18}$ bacterial adherence increased with time, reaching a peak at $48-72 \mathrm{~h}$ and then a gradual decrease occurred.

Our results, showing that protein coating of catheters reduced coagulase-negative staphylococci (CNS), concur with those of Muller et al. ${ }^{19}$ who reported that catheters coated with protein in vitro bound fewer CNS than uncoated catheters. Regardless of the underlying surface topography, a similar surface appears to be presented to bacteria when long-dwell and control catheters become coated with protein. Although catheter surface microrugosity may be a contributing factor to the initial adherence of bacteria to CAPD catheters in some circumstances, it is unlikely to be a major influence in vivo when proteinaceous material is in contact with the catheter surface.

We are grateful for the financial support of the Northern Ireland Kidney Research Fund, EHSSB and the Pharmaceutical Society of Northern Ireland. The assistance of the staff of the Renal Unit (BCH) and QUB Electron Microscopy Unit is gratefully acknowledged.

\section{References}

1. Mawhinney WM, Adair CG, Gorman SP. Development and treatment of peritonitis in continuous ambulatory peritoneal dialysis. Int J Pharm Pract 1991; 1: 10-18

2. Mawhinney WM, Adair CG, Gorman SP. Examination of microbial biofilm on peritoneal catheters by electron and confocal laser scanning microscopy. Proceedings of the 10th Pharmaceutical Technology Conference, Bologna, Italy. $1991 ; 2: 652-660$.

3. Gorman SP. Microbial adherence and biofilm production. In Denyer SP, Hugo WB (eds) Mechanisms of action of chemical biocides: their study and exploitation. The Society for Applied Bacteriology Technical Series No. 27, Blackwell Scientific Publications, Oxford. 1991: 271-295.

4. Schmitt DD, Bandyk DF, Pequet AJ, Malangoni MA, Towne

JB. Mucin production by Staphylococcus epidermidis. A virulence factor promoting adherence to vascular grafts. Arch Surg 1986; 121: 89-95.

5. Dickinson GM, Bisno AL. Infections associated with indwelling devices: concepts of pathogenesis. Infections associated with intramuscular devices. Antimicrob Agents Chemother 1989; 33: 597-601

6. Dinen P. The effect of suture material in the development of vascular infection. Vasc Surg 1977; 11: 29-33.

7. Muller WA, Cohn LH, Schoen FJ. Infection within a degenerated Starr-Edwards silicone rubber poppet in the aortic valve position. Am J Cardiol 1984; 54: 1146.

8. Fessia SL, Amirana O, Carr KL. Biofilm formation on commercially available plastic tubings. Adv Perit Dial $1988 ; 4: 253-256$

9. Ludlam HA, Noble WC, Marples RR, Philips I. The evaluation 
of a typing scheme for coagulase-negative staphylococci suitable for epidemiological studies. J Med Microbiol 1989; 30: $161-165$.

10. Gorman SP, McCafferty DF, Woolfson AD, Jones DS Reduced adherence of microorganisms to human mucosal epithelial cells following treatment with Taurolin, a novel antimicrobial agent. $J$ Appl Bacteriol 1987; 62: 315-320.

11. Holmes CJ, Evans RC, Vonesh E. Application of an empirically derived growth curve model to characterize Staphylococcus epidermidis biofilm development on silicone elastomer. Biomaterials 1989; 10 : 625-629.

12. Woolfson AD, Gorman SP, McCafferty DF, Jones DS. On the statistical evaluation of adherence assays. J Appl Bacteriol 1987; 63: 147-151.

13. Diaz-Blanco J, Clawson RC, Roberson SM, Sanders CB, Pramanik AK, Herbst JJ. Electron microscopic evaluation of bacterial adherence to polyvinyl chloride endotracheal tubes used in neonates. Crit Care Med 1989; 17: 1335-1340.

14. Wilkins KM, Martin GP, Hanlon GW, Marriott C. The influence of critical surface tension and microrugosity on the adhesion of bacteria to polymer monofilaments. Int $J$ Pharm 1989; 57: 1-7.

15. Gaylarde CC, Videla HA. Localised corrosion induced by a marine vibrio. Int Biodeter 1987; 23: 91-104.

16. Holah JT, Thorpe RH. Cleanability in relation to bacterial retention on unused and abraded domestic sink materials. J Appl Bacteriol 1990; 69: 599-608.

17. Carballo J, Ferreiros CM, Criado MT. Importance of experimental design in the evaluation of the influence of proteins in bacterial adherence to polymers. Med Microbiol Immunol 1991; 180: 149-155.

18. Martinez-Martinez L, Pascual A, Perea EJ. Kinetics of adherence of mucoid and non-mucoid Pseudomonas aeruginosa to plastic catheters. J Med Microbiol 1991; 34 : $7-12$.

19. Muller E, Takeda S, Goldmann DA, Pier GB. Blood proteins do not promote adherence of coagulase-negative staphylococci to biomaterials. Infect Immun 1991; 59: 3323-3326. 